\title{
Low concentration of ethanol induce apoptosis in HepG2 cells: role of various signal transduction pathways
}

\author{
Francisco Castaneda and Sigrid Rosin-Steiner \\ Laboratory for Molecular Pathobiochemistry and Clinical Research, Max Planck Institute of Molecular Physiology, \\ Dortmund, Germany
}

Correspondence to: Francisco Castaneda, MD, Laboratory for Molecular Pathobiochemistry and Clinical Research, Max Planck Institute of Molecular Physiology, Otto-Hahn-Str. 11, 44227 Dortmund, Germany. Tel. 49-231-9742-6490, Fax. 49-231-133-2699, E-mail: francisco.castaneda@mpi-dortmund.mpg.de

Received: 2006.09.11; Accepted: 2006.10.25; Published: 2006.10.31

As we previously demonstrated in human hepatocellular carcinoma (HepG2) cells, ethanol at low concentration triggers the Fas apoptotic pathway. However, its role in other intracellular signaling pathways remains unknown. Therefore, the aim of the present study was to evaluate the role of low concentration of ethanol on different intracellular signaling pathways. For this purpose, HepG2 cells were treated with $1 \mathrm{mM}$ ethanol for $10 \mathrm{~min}$ and the phosphorylation state of protein kinases was determined. In addition, the mRNA levels of transcription factors and genes associated with the Fas apoptotic pathway were determined. Our data demonstrated that ethanol-induced phosphorylation of protein kinases modulates both anti-apoptotic and pro-apoptotic mechanisms in HepG2 cells. Pro-apoptosis resulted mainly from the strong inhibition of the G-protein couple receptor signaling pathway. Moreover, the signal transduction initiated by ethanol-induced protein kinases phosphorylation lead to increased expression of the transcription factors with subsequent expression of genes associated with the Fas apoptotic pathway (Fas receptor, Fas ligand, FADD and caspase 8). These results indicate that low concentration of ethanol exert their effect by predominant activation of pro-apoptotic events that can be divided in two phases. An early phase characterized by a rapid transient effect on protein kinases phosphorylation, after 10 min exposure, with subsequent increased expression of transcription factors for up to 6 hr. This early phase is followed by a second phase associated with increased gene expression that began after $6 \mathrm{hr}$ and persisted for more than $24 \mathrm{hr}$. This information provided a novel insight into the mechanisms of action of ethanol $(1 \mathrm{mM})$ in human hepatocellular carcinoma cells.

Key words: Ethanol, HepG2 cells, protein kinases, signal transduction, transcription factors, gene expression

\section{Introduction}

Apoptosis is a highly organized form of cell death that takes place in normal physiological processes, such as development, homeostasis, tissue turnover, and immune response. Hereby, a balance between cell survival and cell death (apoptosis and necrosis) is mandatory. Apoptosis also plays an important role in different pathological conditions (i.e. cancer, autoimmune disease and neurodegeneration) including alcoholic liver disease (ALD) [1].

The toxic effect of ethanol in the liver has been extensively demonstrated in several animal and clinical studies [2-8]. The hepatotoxic effect of ethanol directly correlates with time of exposure and the applied concentration [2-5]. High concentrations of ethanol lead to necrotic cell death [6]. This results from induction of the cytochrome P4502E1 (CYP2E1) with subsequent production of reactive oxygen species $[5,7$, 8]. Interestingly, ethanol at low concentration causes apoptosis preferentially [9-11]. At such low concentration, ethanol-induced apoptosis in human hepatocellular carcinoma (HepG2) cells is triggered by activation of the Fas receptor [12], a member of the tumor necrosis family, with subsequent activation of the intracellular adapter protein FADD (Fas Associated Death Domain) and caspase-8 [13, 14]. Caspase-8 represents the key component of ethanol-induced apoptosis when applied at low concentration, as confirmed by completely suppressing apoptosis after caspase-8 inhibition [12].

Fas receptor activation has been involved not only with the apoptotic process, but also with triggering of other intracellular signaling pathways [15, 16]. These include the mitogen-activated protein kinase (MAPK) pathway [13, 17-19], and the transcription factor $\mathrm{NFKB}$ signal cascade $[20,21]$. However, the effect of low concentration of ethanol in the intracellular signaling pathways activated by the Fas receptor pathway has not been documented. Therefore, the aim of the present study was to determine the effect of ethanol exposure at low concentration $(1 \mathrm{mM})$ on protein kinases phosphorylation in human hepatocellular carcinoma (HepG2) cells. In addition, the effect of protein kinases phosphorylation on the expression of transcription factors and subsequent gene expression was determined.

Low concentration of ethanol seems to have a potential therapeutic effect for the treatment of human 
hepatocellular carcinoma; however, its mechanisms of action remain to be determined. This work represent the first step in our understanding of the pathophysiological mechanisms associated with ethanol exposure at low concentration, which are needed to establish its use as a potential target for the treatment of human hepatocellular carcinoma.

\section{Methods}

\section{Human hepatocellular carcinoma (HepG2) cells}

HepG2 cells, derived from human hepatocellular carcinoma (obtained from Deutsches Krebsforschungszentrum Heidelberg, Germany) were seeded in $250 \mathrm{ml}$ tissue culture flasks (Falcon-Becton Dickinson, Heidelberg, Germany) at $1 \times 10^{5} / \mathrm{ml}$ concentration in $10 \mathrm{ml}$ RPMI-1640 medium supplemented with $10 \%$ fetal bovine serum (Boehringer Mannheim, Mannheim, Germany), 100 $\mathrm{U} / \mathrm{ml}$ penicillin and $100 \mu \mathrm{g} / \mathrm{ml}$ streptomycin (ICN Flow, Meckenheim, Germany) at $37^{\circ} \mathrm{C}$ in a humidified atmosphere of $7.5 \% \mathrm{CO}_{2}$. After 7 days of cell culture, the cells were harvested with $0.05 \%$ trypsin / $0.02 \%$ EDTA (Gibco BRL, Eggersheim, Germany). Cells were seeded in 6-well plates (Falcon-Becton Dickinson, Heidelberg, Germany) at concentrations of $1 \times 10^{5} / \mathrm{ml}$. Six sets of experiments were performed $(n=6)$. Each set consist of two groups as follow: HepG2 cells treated with $1 \mathrm{mM}$ ethanol and HepG2 cells without ethanol treatment as a control.

The rationale for using a low concentration of ethanol, namely $1 \mathrm{mM}$, was based on previous reported studies in which the potential therapeutic effect of such concentrations has been proposed [11]. In addition, human hepatocellular carcinoma (HepG2) cells were studied without comparing against normal hepatocytes because of the way HepG2 cells metabolize ethanol and because of the selective induction of apoptosis without necrosis observed in HepG2 cells exposed to $1 \mathrm{mM}$ ethanol [9], which has not been observed in normal hepatocytes.

\section{Assessment of protein kinases phosphorylation}

For protein kinase phosphorylation studies, HepG2 cells were exposed to low ethanol concentration ( $1 \mathrm{mM}$; Merck, Darmstadt, Germany) for $10 \mathrm{~min}$. After treatment, total cell lysates were prepared as described by Zhang et al. [22]. Briefly, cells were washed twice with ice-cold phosphate-buffered saline (PBS; Gibco BRL, Eggenstein, Germany); scraped in lysis buffer $(20 \mathrm{mM}$ Tris, $20 \mathrm{mM}$ $\beta$-glycerophosphate, $150 \mathrm{mM} \mathrm{NaCl}, 3 \mathrm{mM}$ EDTA, 3 mM EGTA, $1 \mathrm{mM} \mathrm{Na} \mathrm{VO}_{4}, 0.5 \%$ Nonidet P-40, and 1 $\mathrm{mM}$ dithiothreitol); supplemented with $1 \mathrm{mM}$ phenylmethanesulfonyl fluoride, $2 \mu \mathrm{g} / \mathrm{ml}$ leupeptin, 4 $\mu \mathrm{g} / \mathrm{ml}$ aprotinin, and $1 \mu \mathrm{g} / \mathrm{ml}$ pepstatin $\mathrm{A}$; and sonicated for $15 \mathrm{sec}$. Cell debris was removed by centrifugation at $1400 \times \mathrm{g}$ for $30 \mathrm{~min}$ at $4{ }^{\circ} \mathrm{C}$. Protein concentration was determined by the Bradford assay [23]. Protein kinase phosphorylation state was assessed using phospho-antibody screening KPKS-1.0 (Kinexus Bioinformatics Corporation, Vancouver,
Canada). For this, the Kinetikworks protocol was used [24]. Briefly, $300 \mu \mathrm{g}$ of total protein was blotted on a $13 \%$ single lane SDS-polyacrylamide gel and transferred to nitrocellulose membrane. By using a 20-lane multiblotter from Bio-Rad (Munich, Germany), the membrane was incubated with different mixtures of up to three antibodies per lane that react with a 75 known phosphorylated cell signaling proteins of distinct molecular masses. After further incubation with a mixture of relevant horseradish peroxidase-conjugated secondary antibodies (Santa Cruz Biotechnology, Heidelberg, Germany), the blots were developed using ECL Plus reagent (Amersham Biosciences, Freiburg, Germany), and signals were quantified using Quantity One software (Bio-Rad). The obtained values were normalized to untreated HepG2 cells and the phosphorylation change in percent was calculated. All values showing an increase or decrease equivalent to $25 \%$ or more were considered significant.

\section{Assessment of ethanol-induced apoptosis by DNA fragmentation after GPCR inhibition}

Inhibition of G-protein coupled receptors (GPCR) was performed using heparin $(0.10 \mathrm{IU} / \mathrm{ml})$ or pertussis toxin $(20 \mathrm{pM})$. All chemicals were purchased from Sigma Aldrich (Seelze, Germany). HepG2 cells were pre-treated for $30 \mathrm{~min}$ with GPRC inhibitors followed by a washed step and incubated with ethanol $(1 \mathrm{mM})$ for $24 \mathrm{~h}$. Then, ethanol-induced apoptosis was analyzed by a double-fluorescence staining technique with Hoechst 33342 (excitation 330-380 nm, emission 460 nm; Molecular Probes, MoBiTec, Göttingen, Germany) and propidium iodide (excitation $590 \mathrm{~nm}$ and emission $620 \mathrm{~nm}$; Molecular Probes, MoBiTec, Göttingen, Germany) as described previously [25]. Briefly, after 24 hours of ethanol incubation, $20 \mu \mathrm{g} / \mathrm{ml}$ propidium iodide and $100 \mu \mathrm{g} / \mathrm{ml}$ Hoechst 33342 were incubated for $15 \mathrm{~min}$ at $37^{\circ} \mathrm{C}$ in the dark. After staining, the cells were immediately examined using a Leitz DM-IRB fluorescence microscope. The numbers of cells with apoptosis-associated alterations of the nuclei and without membrane barrier dysfunction were determined within a field of view at a magnification of X400. A total of 10 randomly selected fields were counted per well. The numbers of altered cells were averaged an expressed as percentage of total cells.

\section{Quantitative real-time polymerase chain reaction}

Quantitative real-time PCR was used to evaluate the effect of ethanol on mRNA expression level of different transcription factors as well as the expression of genes of the Fas receptor signaling pathway, including Fas receptor, Fas ligand, FADD and caspase 8. Total RNA was isolated from HepG2 cells using RNAsy kit (Qiagen) and RNA quality was evaluated using Agilent RNA 6000 Nano Chip Kit and Bioanalyzer 2100 (Agilent, Böbligen, Germany). Real-time RT-PCR was performed using the QuantiTect SYBR green RT-PCR kit (Qiagen, Hilden, Germany). Specific primers for transcription factor (AP1, SRF, Elk1, Stat1 and NFkB) and members of the Fas receptor signaling pathway (Fas receptor, Fas 
ligand, FADD and caspase 8) were used. Primer design was performed with the Primer Express 2.0 software from ABI Prism, Applied Biosystems (Darmstadt, Germany) and obtained from MWG-Biotech AG (Ebersberg, Germany). Fas receptor forward, 5'-CTT TTC GTG AGC TCG TCT CTG A-3'; Fas receptor reverse, 5'-CTC CCC AGA AGC GTC TTT GA-3'; Fas ligand forward, 5'-CCA GCT TGC CTC CTC TTG AG-3'; Fas ligand reverse, 5'-TCC TGT AGA GGC TGA GGT GTC A-3'; FAAD forward, 5'-GGT GGA GAA CTG GGA TTT GAA C-3'; FAAD reverse, 5'-CGC CAC AGT GGT TGA GCA T-3'; caspase 8 forward, 5'-GCA AAA GCA CGG GAG AAA GT-3'; and caspase 8 reverse, 5'-TGC ATC CAA GTG TGT TCC ATT C-3'. Quantitative real-time PCR determination using the Optical System Software (iQ5 version 1.0) provided with the BioRad iQ5 cycler (BioRad, Munich, Germany) was performed.

\section{Statistical Analysis}

Data are expressed as mean values \pm standard deviation (SD). Results from HepG2 cells treated with $1 \mathrm{mM}$ concentration of ethanol were compared to non-treated HepG2 cells (control cells) using Student's t-test. Statistical significance was assumed at $p$ level $<0.05$ level. SigmaPlot software version 8.02 (Systat Software, Erkrath, Germany) was used for statistical analysis.

\section{Results}

\section{Short exposure to $1 \mathrm{mM}$ ethanol induces phosphorylation of protein kinases}

Table 1 shows the effect of $1 \mathrm{mM}$ ethanol on protein kinases phosphorylation in HepG2 cells after $10 \mathrm{~min}$ exposure time compared to untreated cells. Ethanol caused a strong inhibition of the GPCR signaling pathway as shown by phosphorylation of GRK2 and PKCa; with values of $109 \%$ and $104 \%$, respectively, combined with dephosphorylation of ROKa, PKC $\delta$ and PKC $\mu$; with values of $-56 \%,-44 \%$ and $-28 \%$ of control cells, respectively. These findings resulted in a pro-apoptotic effect that was intensified by a slight inhibition of the JNK and the NFKB signaling pathway as demonstrated by a reduced phosphorylation of MEK4, IKKa, JNK and MEK6; with values of $-36 \%,-33 \%,-27 \%$ and $-26 \%$, respectively. The pro-apoptotic effect was also induced by a slight activation of the cell death receptor signaling pathway with increased phosphorylation of DAPK3 and DAPK1 equivalent to $56 \%$ and $38 \%$, respectively. On the other hand, an anti-apoptotic effect was also activated, as shown by an increased phosphorylation of members of the ERK and the CDK signaling pathways, including ERK2, RSK2, CDK9, CDK6, CDK7 and RSK1 with values of $50 \%, 48 \%, 38 \%, 35 \%, 29 \%$, $26 \%$ and $26 \%$, respectively.

Table 1 Effect of $1 \mathrm{mM}$ ethanol on various signaling transduction pathways leading to apoptosis

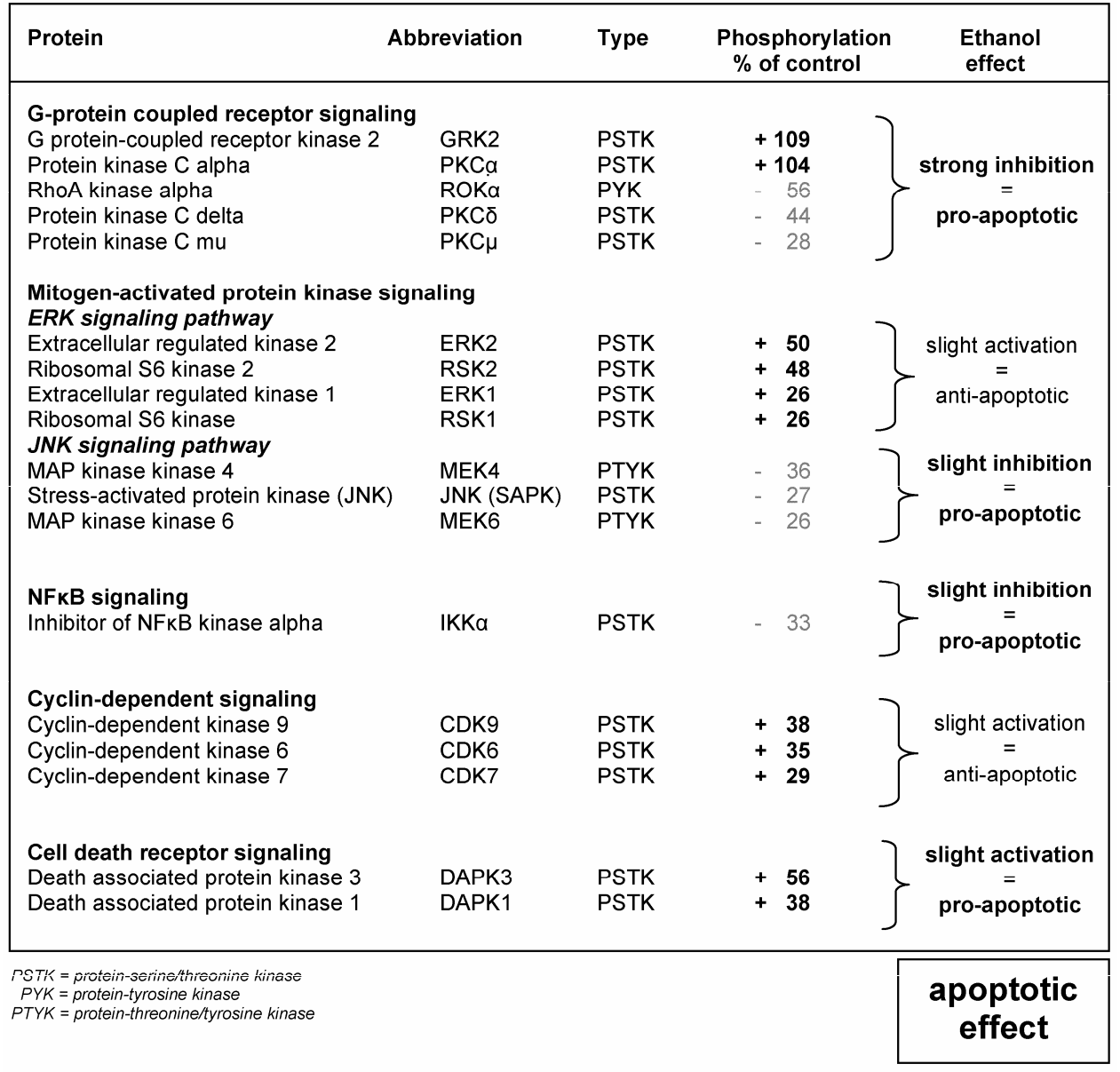




\section{Neutralization of membrane receptors blocks ethanol-induced apoptosis}

Based on the strong inhibition of the G-protein coupled receptor signaling pathway observed after ethanol exposure, we analyzed further the role of this pathway in ethanol-induced apoptosis. For that purpose, experiments with specific inhibitors with subsequent determination of the apoptotic rate were carried out. As shown in Figure 1, we found that ethanol-induced apoptosis after ethanol exposure was increased by $33 \%$ compared to control HepG2 cells (without ethanol exposure). In contrast, specific inhibitors of the G-protein couple receptor, such as heparin and pertussis toxin, resulted in increased apoptosis with values of $45 \%$ and $70 \%$, respectively. These data confirm the role of G-protein coupled receptors as a regulatory mechanism of ethanol-induced apoptosis.

Figure 1 Effect of inhibitors of G-protein coupled receptors (GPCR) on ethanol-induced apoptosis in HepG2 cells. Results are expressed as percent of control HepG2 cells (without ethanol exposure). Results are the mean of six different experiments $(\mathrm{n}=6)$. Error bars represents standard deviations. Significance is shown as the difference between ethanol-treated and control cells $* p<0.05$.

\section{Ethanol-induced protein kinases phosphorylation activates the expression of transcription factors}

Figure 2 shows the effect of a millimolar ethanol concentration on mRNA levels of AP1, Elk1, Stat1, SRF and NFkB after 2, 4 and 6 hours of ethanol exposure using relative quantitative real time PCR. The transcription factor AP1 did not reveal any significant difference after 2, 4 and $6 \mathrm{hr}$ ethanol exposure

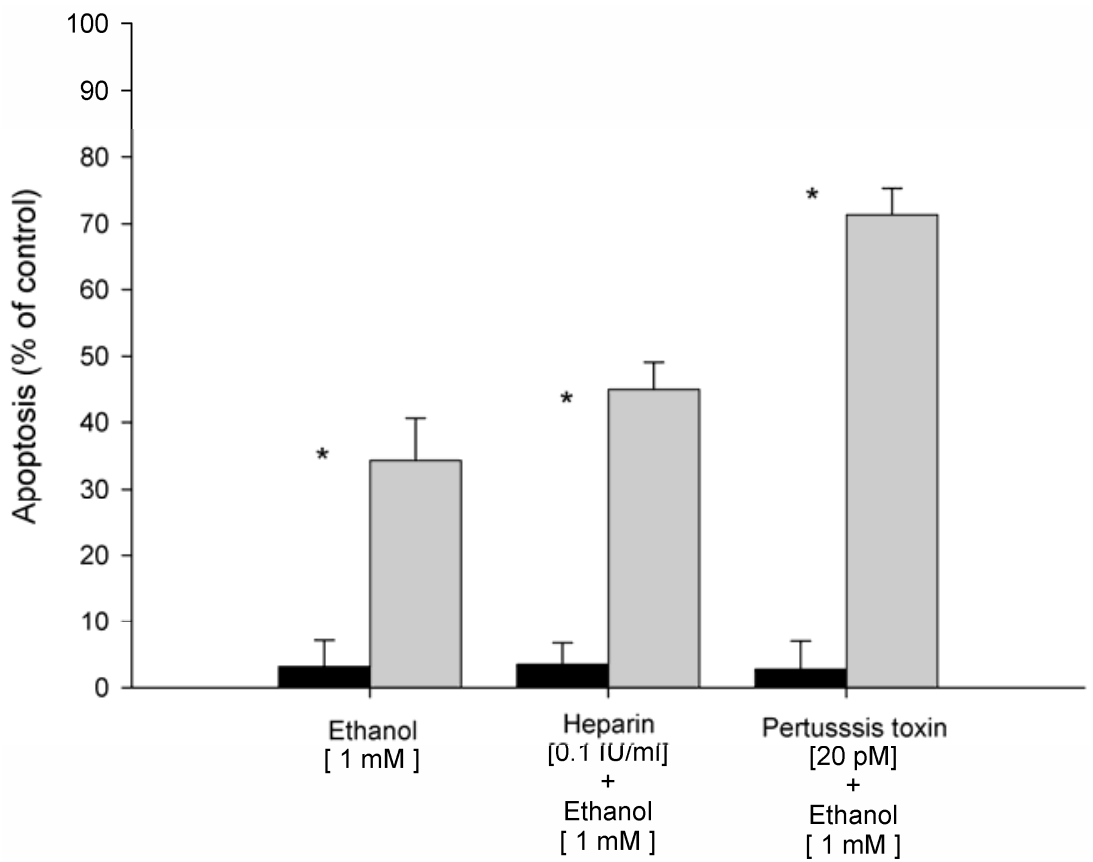
compared to controls. The mRNA expression level of Elk1 and Stat1 showed time dependent increases in mRNA expression levels of approximately 1 -fold after $2 \mathrm{~h}$ of ethanol exposure, and 2-fold after $6 \mathrm{hr}$ exposure. SRF was significantly increased after $2 \mathrm{hr}$ by 7 -fold with subsequent decrease to about only 1 -fold after 4

$\mathrm{hr}$ and $6 \mathrm{hr}$. In contrast, NFKB was significantly increased after $2 \mathrm{hr}$ of ethanol exposure with a maximal effect seen after $6 \mathrm{hr}$, representing increases of 1- and 12-fold, respectively. These data confirm the effect of ethanol on intracellular signal transduction resulting in increased expression of transcription factors.

Figure 2 Time course changes in mRNA levels of transcription factors in HepG2 cells exposed to $1 \mathrm{mM}$ ethanol concentration expressed as a relative fold change compared to control HepG2 cells (not exposed to ethanol). White, gray and black bars represent 2, 4 and $6 \mathrm{hr}$ exposure times, respectively. Results are the mean of six different experiments $(n=6)$. Error bars represents standard deviations. Significance is shown as the difference between ethanol-treated and control cells at $2 \mathrm{~h}(* p<0.05), 4 \mathrm{~h}(\dagger p<$ $0.05)$, and $6 \mathrm{~h}(\# p<0.05)$.

\section{Ethanol regulates the expression of genes of the Fas signaling cascade}

To further investigate the role of ethanol-induced apoptosis on gene expression, the mRNA level of Fas receptor, Fas ligand, FADD, and caspase 8, were examined using relative quantitative real time PCR. As shown in Figure 3,

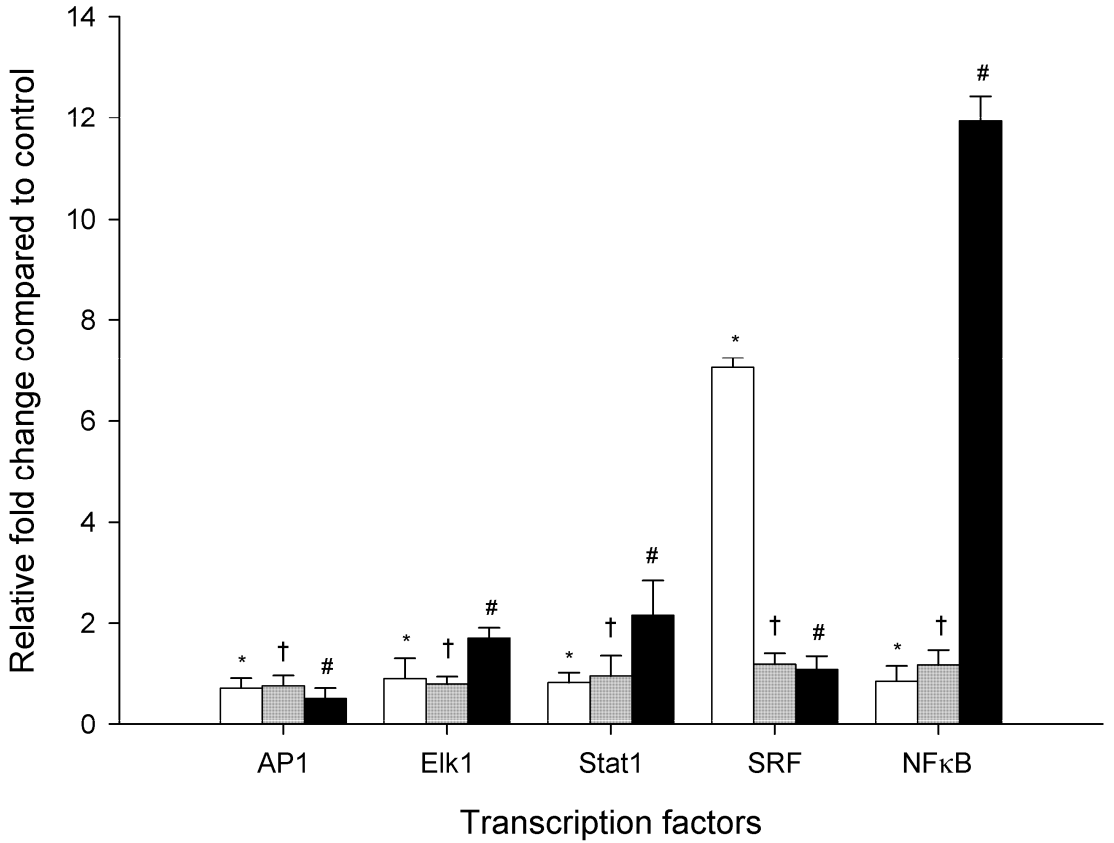


HepG2 cells exposed to ethanol for $6 \mathrm{~h}$ showed significantly increased mRNA expression levels for Fas receptor, Fas ligand, FADD and caspase 8; equivalent to $1.3,1.8,3.7$ and 7.3 -fold, respectively, when compared to cells non treated with ethanol. Fas receptor expression was similar after 6 and $24 \mathrm{hr}$, while
Fas ligand expression significantly increased by 2.7-fold after $24 \mathrm{hr}$ of ethanol exposure. In contrast, mRNA expression of FADD and caspase 8 were significantly decreased by 2.2 and 5.6, respectively, after $24 \mathrm{hr}$ exposure of ethanol.

Figure 3 mRNA expression levels of members of the Fas signaling cascade in HepG2 cells exposed to 1mM ethanol concentration expressed as a relative fold change compared to control HepG2 cells (not exposed to ethanol). White and black bars represent 6 and $24 \mathrm{hr}$ exposure times, respectively. Results are the mean of six different experiments $(\mathrm{n}=6)$. Error bars represents standard deviations. Significance is shown as the difference between ethanol-treated and control cells at $6 \mathrm{~h}$ $(* p<0.05)$ and $24 \mathrm{~h}(\dagger p<0.05)$.

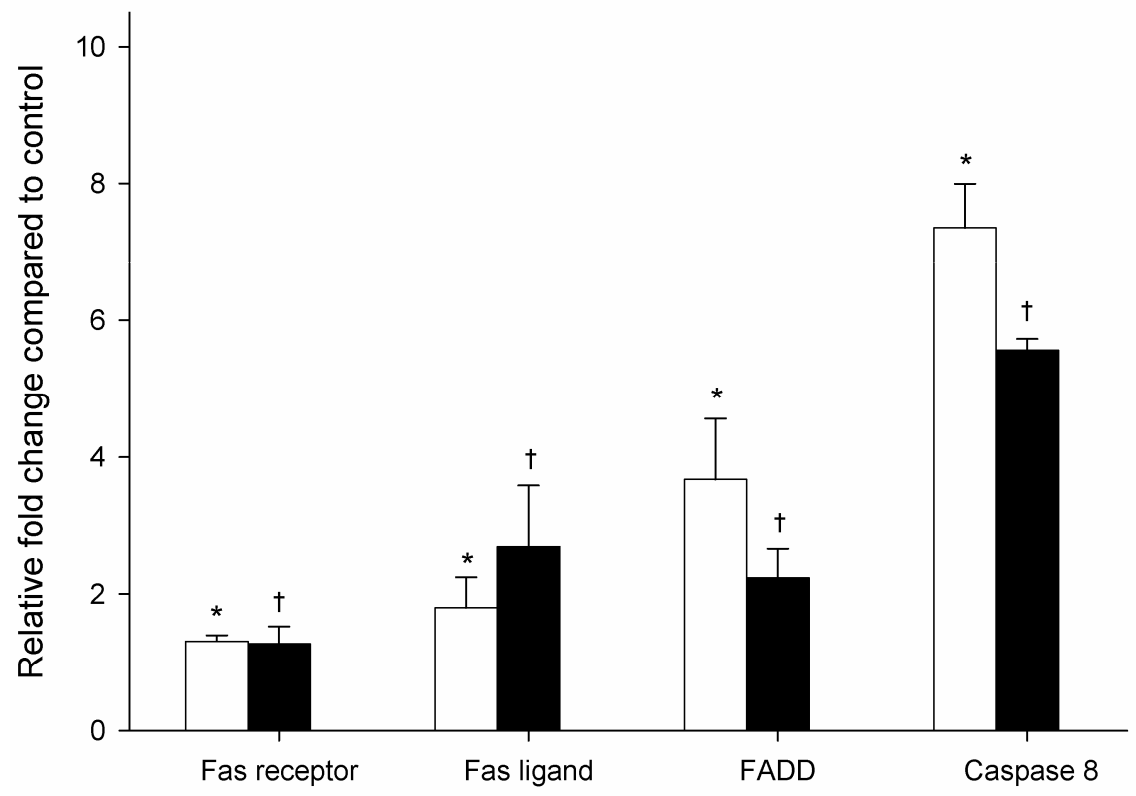

\section{Discussion}

The working hypothesis of the present study was that apoptosis induced by low concentration of ethanol (namely $1 \mathrm{mM}$ ) in HepG2 cells is regulated through the interaction of both pro-apoptotic and anti-apoptotic signaling pathways. The pro-apoptotic effect induced by ethanol was demonstrated by a strong inhibition of GPCR signaling pathway in association with a slight inhibition of JNK and NFKB signaling in association with a slight activation of the cell death receptor signaling. In addition, ethanol also phosphorylated protein kinases belonging to signal transduction pathways with an anti-apoptotic effect such as ERK and CDK. These data, corroborate that ethanol-induced phosphorylation of protein kinases modulates both anti-apoptotic and pro-apoptotic mechanisms, and suggests that ethanol at low concentration shifts the balance into the apoptotic direction after its initial effect on protein kinases phosphorylation.

The most strikingly and novel finding obtained hereby was the strong inhibition of the GPCR signaling pathway induced mainly by increased phosphorylation of GRK2. This finding suggests an important regulatory role of ethanol-induced apoptosis through early phosphorylation of GRK2. Our data correlates with the reported involvement of this protein kinase in the regulation of signal transduction initiated through the GPCR [26, 27]. Furthermore, the regulatory mechanism of ethanol-induced apoptosis through the GPCR signaling pathway was also confirmed by the increased apoptotic rate observed after neutralization of GPCR. These findings provide a novel insight into the molecular mechanism of action exerted by the exposure of $1 \mathrm{mM}$ ethanol concentration in human hepatocellular HepG2 cells.

We found that ethanol-induced phosphorylation of protein kinases lead to an increased expression of transcription factors (AP1, Elk1, Stat1, SRF and NFkB). This finding correlates with the reported activation of transcriptions factors through the different signaling pathways [28-32]. In addition, the observed increased expression of transcription factors subsequently resulted in an induction of gene expression, which seems to be also regulated through the interaction of various intracellular signaling pathways. It has been reported that MAPK signal cascade induces Fas ligand expression as well as Fas ligand promoter activation in T lymphocytes [33]. Our data confirmed the increased expression of genes associated with the Fas-signaling cascade (including Fas receptor, Fas ligand, FADD and caspase 8).

The NFKB signaling pathway is known to be one of the key regulators of anti-apoptotic processes observed in human hepatocytes derived cell lines [34, 35]. Studies performed in T cells have demonstrated 
that the NFKB signaling pathway mediates cell growth and protection against apoptotic cell death [36]. The kinase IKKa plays a key step in the activation of NFKB [37]. Our data demonstrated that ethanol inhibits the anti-apoptotic effect of the NFkB signaling pathway by reducing the phosphorylation of IKKa. Moreover, the increased expression of mRNA levels of NFKB after 6 $\mathrm{hr}$ of ethanol exposure, suggests a regulatory role of this pathway in ethanol-induced apoptosis.

Taking these data together, we propose a regulatory mechanism of ethanol-induced apoptosis in HepG2 cells (as described in Figure 4 and 5). This regulatory mechanism results from the balanced interaction between pro-apoptotic and anti-apoptotic effects of various intracellular signaling pathways. Specifically, ethanol at low concentration induced a biphasic effect in HepG2 cells, characterized by a rapid transient effect on protein kinases, after $10 \mathrm{~min}$ exposure, followed by increased expression of transcription factors up to $6 \mathrm{hr}$ (early events phase) and a second persistent activation of gene expression that began after $6 \mathrm{hr}$ and persisted for more than $24 \mathrm{hr}$ (late events phase). The early events phase was characterized by significant change in the phosphorylation state of protein kinases with subsequent induction of transcription factors. Such changes were associated with either inhibition or activation of various intracellular signaling pathways leading to a pro-apoptotic effect. These findings suggest that low concentration of ethanol shifts the balance into the apoptotic direction after its initial effect on protein kinases. The second phase or late events, between 6 and $24 \mathrm{hr}$ is characterized by expression of Fas-associated genes (including Fas receptor, Fas ligand, FADD and caspase 8).

Figure 4 Regulatory mechanism of low concentration of ethanol resulting from the balanced interaction between pro-apoptotic and anti-apoptotic effects of various intracellular signaling pathways.

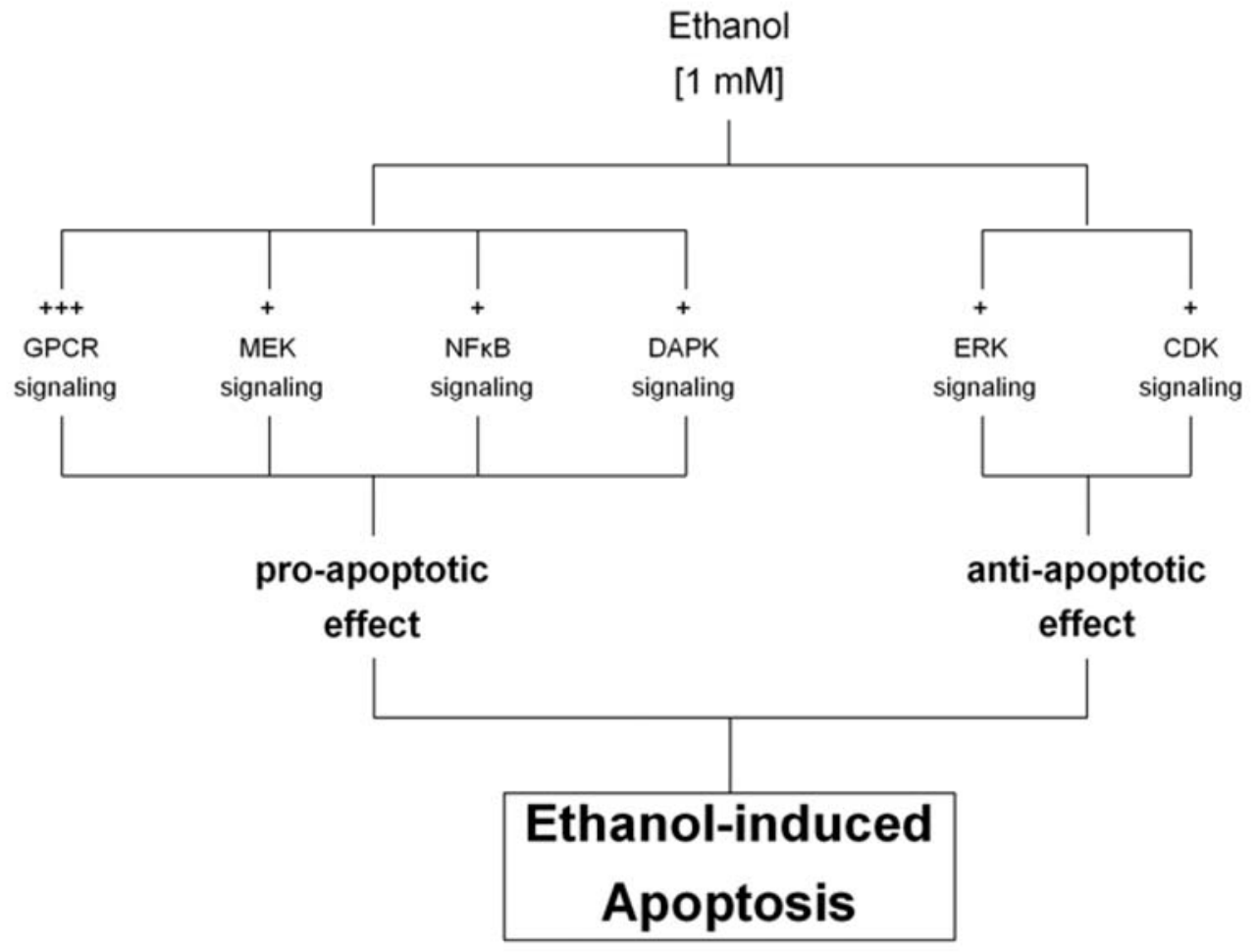


Figure 5 Proposed model of the regulatory mechanisms associated with ethanol-induced apoptosis in HepG2 cells exposed to $1 \mathrm{mM}$ ethanol concentration.

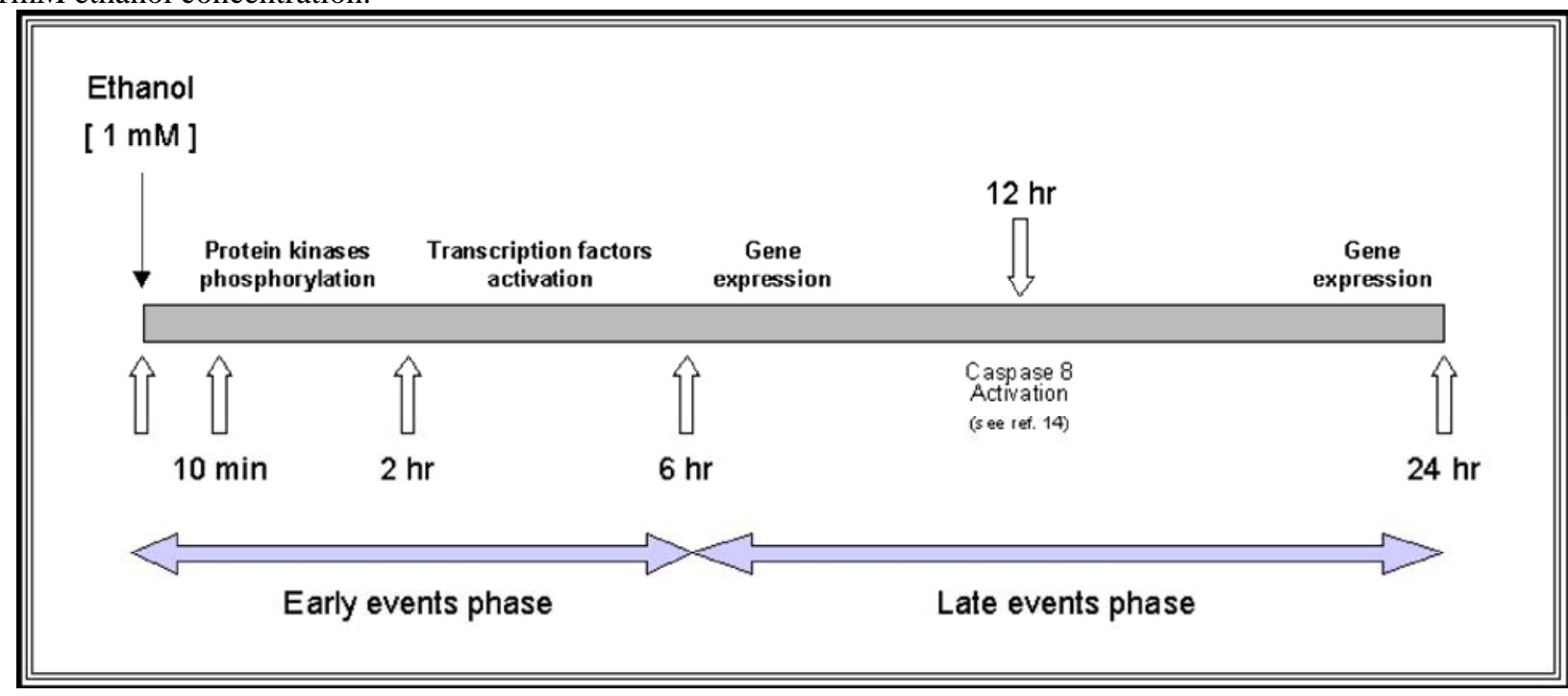

In this study, treatment with $1 \mathrm{mM}$ ethanol concentration induced up-regulation of caspase 8, which is the key molecule of ethanol-induced apoptosis through Fas receptor activation. These data corroborate the increased activity of caspase 8 previously reported after $12 \mathrm{hr}$ of ethanol exposure [12]. This finding suggests that low concentration of ethanol plays a very important role in the modulation of ethanol-induced apoptosis through simultaneous induction of anti- and pro-apoptotic events. Thus, apoptosis induced by a low concentration of ethanol seems to be regulated by protective mechanisms resulting from activation of anti-apoptotic pathways. Moreover, the interaction between both pro- and anti-apoptotic processes, induced by short-term exposure of ethanol at low concentration, does represent an important new mechanism to consider in the pathophysiology of ethanol-induced effects on HepG2 cells.

In conclusion, the data obtained in the present study support our working hypothesis and confirm a balance between pro- and anti-apoptotic effects. Ultimately, the fine balance between these two processes would lead to a controlled regulation of ethanol-induced apoptosis in HepG2 cells exposed to low concentrations of ethanol. The findings of the present study provide new evidence that ethanol at low concentration is not simply an activator of Fas receptor-induced apoptosis. This model represents the basis for further studies addressing the pathophysiological mechanisms of exposure to low concentration of ethanol in HepG2 cells, and provides information about potential targets for the treatment strategies of human hepatocellular carcinoma.

\section{Acknowledgements}

We thank Dr. Rolf K-H. Kinne for his valuable support.

\section{Conflicts of interest}

The authors have declared that no conflict of interest exists.

\section{References}

1. Higuchi H, Gores GJ. Mechanisms of liver injury: an overview. Curr Mol Med 2003;3:483-90.

2. Thurman RG, Bradford BU, Iimuro $Y$, et al. Mechanisms of alcohol-induced hepatotoxicity: studies in rats. Frontiers Biosci 1999;4:e42-e46.

3. Lieber CS. Alcohol and the liver: metabolism of alcohol and its role in hepatic and extrahepatic diseases. Mount Sinai J Med 2000;67:84-94.

4. Lieber CS. Alcoholic liver injury: pathogenesis and therapy in 2001. Pathol Biol 2001;49:738-52.

5. Jaeschke H, Gores GJ, Cederbaum AI, et al. Mechanisms of hepatotoxicity. Toxicol Sci 2002;65:166-76.

6. Hoek JB, Cahill A, Pastorino JG. Alcohol and mitochondria: a dysfunctional relationship. Gastroenterol 2002;122:2049-63.

7. Mari M, Wu D, Nieto N, et al. CYP2E1-dependent toxicity and up-regulation of antioxidant genes. J Biomed Sci 2001;8:52-8.

8. Zima T, Kalousova M. Oxidative stress and signal transduction pathways in alcoholic liver disease. Alcohol Clin Exp Res 2005;29:110S-15S.

9. Castaneda F, Kinne RKH. Short exposure to millimolar concentrations of ethanol induces apoptotic cell death in multicellular HepG2 spheroids. J Cancer Res Clin Oncol 2000;126:305-10.

10. Castaneda F, Kinne RK. Cytotoxicity of millimolar concentrations of ethanol on HepG2 human tumor cell line compared to normal rat hepatocytes in vitro. J Cancer Res Clin Oncol 2000;126:503-10.

11. Castaneda F, Kinne RKH. Ethanol treatment of hepatocellular carcinoma: high potentials of low concentrations. Cancer Biol Ther 2004;3:430-33.

12. Castaneda F, Kinne RKH. Apoptosis induced in HepG2 cells by short exposure to millimolar concentrations of ethanol involves the Fas-receptor pathway. J Cancer Res Clin Oncol 2001;127:418-24.

13. Diehl AM. Effect of ethanol on tumor necrosis factor signaling during liver regeneration. Clinical Biochemistry 1999;32:571-78.

14. Yoon JH, Gores GJ. Death receptor-mediated apoptosis and the liver. Journal of Hepatology 2002;37:400-10. 
15. Diehl AM. Cytokines and the molecular mechanisms of alcoholic liver disease. Alcohol Clin Exp Res 1999;23:1419-24.

16. Diehl AM. Cytokine regulation of liver injury and repair. Immunol Rev 2000;174:160-71.

17. Baker SJ, Reddy EP. Transducers of life and death: TNF receptor superfamily and associated proteins. Oncogene 1996;12:1-9.

18. Hoek JB, Pastorino JG. Cellular signaling mechanisms in alcohol-induced liver damage. Semin Liver Dis 2004;24:257-72.

19. Aroor AR, Shukla SD. MAP kinase signaling in diverse effects of ethanol. Life Sciences 2004;74:2339-64.

20. Shen K, Novak RF. Fas-signaling and effects on receptor tyrosine kinase signal transduction in human breast epithelial cells. Biochem Biophys Res Commun 1997;230:89-93.

21. Chan H, Bartos DP, Owen-Schaub LB. Activation-dependent transcriptional regulation of the human fas promoter requires NF-kB p50-p65 recruitment. Mol Cell Biol 1999;19:2098-108.

22. Zhang $H$, Shi $X$, Hampong $M$, et al. Stress-induced inhibition of ERK1 and ERK2 by direct interaction with p38 MAP kinase. J Biol Chem 2001;276:6905-8.

23. Bradford MM. A rapid and sensitive method for the quantitation of microgram quantities of protein utilizing the principle of protein-dye binding. Anal Biochem 1976;72:248-54.

24. Pelech S, Sutter C, Zhang H. Kinetworks protein kinase multiblot analysis. Methods Mol Biol 2003;218:99-111.

25. Castaneda F, Kinne RKH. Effects of doxorubicin, mitomycin C, and ethanol on Hep-G2 cells in vitro. J Cancer Res Clin Oncol 1999;125:1-8.

26. Higashi $K$, Hoshino M, Nomura $T$, et al. Interaction of protein phosphatases and ethanol on phospholipase C- mediated intracellular signal transduction processes in rat hepatocytes: role of protein kinase A. Alcohol Clin Exp Res 1996;20:320A-24A.

27. Lorenz K, Lohse MJ, Quitterer U. Protein kinase C switches the Raf kinase inhibitor from Raf-1 to GRK-2. Nature 2003;426:574-9.

28. Lenczowski JM, Dominguez L, Eder AM, et al. Lack of a Role for Jun Kinase and AP-1 in Fas-Induced Apoptosis. Mol Cell Biol 1997;17:170-81.

29. Poser S, Impey $S$, Trinh $K$, et al. SRF-dependent gene expression is required for PI3-kinase-regulated cell proliferation. Embo J 2000;19:4955-66.

30. Siehler S, Manning DR. Pathways of transduction engaged by sphingosine 1-phosphate through $\mathrm{G}$ protein-coupled receptors. Biochim Biophys Acta 2002;1582:94-9.

31. Sagi SA, Seasholtz TM, Kobiashvili M, et al. Physical and functional interactions of Galphaq with Rho and its exchange factors. J Biol Chem 2001;276:15445-52.

32. Yang SH, Sharrocks AD. Convergence of the SUMO and MAPK pathways on the ETS-domain transcription factor Elk-1. Biochem Soc Symp 2006:121-9.

33. Faris M, Kokot N, Latinis $\mathrm{K}$, et al. The c-Jun N-terminal kinase cascade plays a role in stress-induced apoptosis in Jurkat cells by up-regulating Fas ligand expression. J Immunol 1998;160:134-44.

34. Lee FS, Hagler J, Chen ZJ, et al. Activation of the IkappaB alpha kinase complex by MEKK1, a kinase of the JNK pathway. Cell 1997;88:213-22.

35. Marusawa H, Hijikata $M$, Watashi $K$, et al. Regulation of Fas-mediated apoptosis by NF-kappaB activity in human hepatocyte derived cell lines. Microbiol Immunol 2001;45:483-9.

36. Rivera-Walsh I, Cvijic ME, Xiao G, et al. The NF-kappa B signaling pathway is not required for Fas ligand gene induction but mediates protection from activation-induced cell death. J Biol Chem 2000;275:25222-30.

37. Baldwin AS Jr. The NF-kappa B and I kappa B proteins: new discoveries and insights. Annu Rev Immunol 1996;14:649-83. 